\section{Study of the Surface-Markings of the Planets in I890.}

THE progress of astronomy during the year 1890 has been noteworthy in many ways. Some of the important particulars will be given briefly in the references that follow.

The study of the surface-markings of the planets has had a leading place in the work of astronomers giving special attention to observation of this kind. The most startling announcements that have appeared this year are those made by the distinguished Schiaparelli of Milan, Italy, concerning the rotation periods of the planets Mercury and Venus. The first publication of this wonderful discovery, that we know of, was made Dec. 8,1889 , in a public address by Schiaparelli, before the Accademia dei Lincei of Rome, in a special sitting, attended by the King and Queen of Italy.

The discovery was by no means accidental. It was made in the usual way of determining the rotation time of a planet, and that was by observing spots on the surface; and the conclusion reached is, that the rotation time of the planet Mercury is the same as its period of revolution around the sun, its axis being nearly perpendicular to the plane of its orbit. The markings were faint, said to be exceedingly difficult to observe, and Schiaparelli has also found the same thing to be true in regard to the rotation of the planet Venus.

M. Perrotin, director of the observatory at Nice, made a series of observations on the markings of the planet Venus for seventyfour days between May and October, for the purpose of testing for himself Schiaparelli's results. His conclusion is, that the rotation time of the planet Venus does not differ from the time of revolution around the sun more than thirty days, making its time of rotation somewhere between one hundred and ninety-five and two hundred and twenty-five days. He also finds that the axis of the planet is almost perpendicular to the plane of its orbit. The displacement of the white region, observed at the northern edge of the terminator, indicates a difference not to exceed fifteen degrees, as was admitted by Schiaparelli. This important work materially strengthens the views of Schiaparelli.

Coming nearer home in our study of the surface-markings of the planets, it should be mentioned that the change of latitude, or the variation of latitude on the earth's surface, should be mentioned as a question of much interest in scientific periodicals for the year 1890. Significant and unexplained results are found in the records of some of the oldest observatories in the world that indicate a change in latitude.

At a meeting some time ago, the International Geodetic Association discussed this important question; and at another soon to be held, if deemed wise, plans will be made to undertake an extended series of observations by observatories in both hemispheres, for the purpose of determining whether or not the latitude of a place is constant, or a variable quantity. Professor Porro of the Royal University of Turin is much interested in pushing this work forward.

In this country the study of the markings of the planet Mars for the last year received as much, if not more, careful attention by Professor W. H. Pickering of Harvard College Observatory than by any one else. Although the last opposition was not a favorable one for the delicate and severe work required of one who can observ6 the " canal" system of Mars, it gives us pleasure to record what he did. His work was by photography at Mount Wilson, California, and by visual observation at Cambridge, Mass., using the Boyden 12-inch refractor.

His attention was directed to two points, - the colors exhibited by the planet, and the finer detail upon the surface. In regard to surface delineation, he thinks that Green's map gives much the best idea of the appearance of the planet, and the general shape of the details, of any thing yet published; and still his observations at Cambridge give considerable fine detail not shown on Green's map, all of which agrees more or less with that reported by Schiaparelli. Professor Pickering regards the name "canal" as a very unfortunate term by which to designate the strange surfacemarkings, because there is not the slightest evidence to support the supposition that they are filled with water: on the contrary, such a view is a very improbable one. Though he can see a large part of this surface delineation, he is not able to see the markings called "canals" double, as described by Schiaparelli. He deservedly expressed great admiration for the patient study and the keen eye of the astronomer who could discover details of Mars with an eight-inch telescope, because of the great difficulty of seeing them with larger instruments when their places and characters are known. During the present year Schiaparelli has reviewed his former work on the study of Mars' surface; and a report of the same appears, by Dr. F. Terby of the Academy of Belgium, in the November number of $L$ 'Astronomie. This late account of the work of the original discoverer is important, in that it confirms his former results, and adds to them interesting details in regard to the apparent widening of some of the canals, and the apparent change of duplicity in the different parts of the same canals at different times. This report will be read with great interest, because it strongly confirms Schiaparelli's former views, which have been cautiously entertained by astronomers generally.

The most interesting work on the detailed study of Jupiter during the past year is by J. E. Keeler of the Lick Observatory. His drawings, made by the aid of the 33-inch equatorial during the months of July and October, are most excellent specimens of sharp delineation in variety of detail. The fine shading of the belts, the Great Red Spot in distinct outline, with the broken bands veering in latitude as they pass the spot, the round white spots, the oblong dark spots tinged with red at the bottom, and the satellite and its shadow in transit, are some of the very interesting features of Jupiter's surface-markings which Mr. Keeler has put on record in these drawings. The new features about the oval spots are their shape and red color at the base. By other observers they have been spoken of as round, and we do not recall that others have noticed the color which they all show at the bottom. This is doubtless due to the superior power of the Lick telescope. Taking into account the fact that Professor Young has seen a veiling of the Great Red Spot,- something like a white film over it, if we understand his words, - and the views of Mr. Keeler shown in his drawings, where the dense dark clouds are bent about it as they pass it, and something of the same color as that of the Great Spot seen at the base of the dark oval spots on the other side of Jupiter's equator, it seems as if signs of important changes in the surface character of the giant planet are constantly going on before our eyes from year to year.

We are sorry that Mr. Keeler's fine drawings have not been published in this country. They have nearly all appeared in foreign scientific journals.

WM. W. PAYNe.

Carleton College Observatory, Dec. 16.

\section{Snake Hill, N.J, as a Locality for Minerals.}

BeING told that there had been some crystals found at Snake Hill, N.J., early in 1888 I started out, accompanied by a young mineralogist, and traversed a road leading across a marsh to the hill, for a distance of five miles. We sought out the quarry where the convicts from Hudson County are educated in the art of blasting. It is about a hundred feet high, and overlooks the Hackensack River.

The hill is an ejection of trap, surrounded by sandstone, the rock being used in macadamizing the county roads. We found several veins of minerals running across the quarry.

The principal minerals which we found and classified are datholite in fine glassy crystals; pectolite in long aggregations of crystals, some exceeding three inches in length and in fibrous radiations; laumonite in fine, needle-like crystals; prehnite in small balls of a beautiful green color; natrolite in fine glassy aggregations of fibrous crystals; analcite in excellent trapezohedrons, some of which measured nearly one inch across; apophyllite in fine transparent square octahedrons, prisms, and tables; gmelinite in excellent aggregations of pink crystals, rhombohedral in form, and modifications of the same, some of which were three-quarters of an inch across; stilbite in prismatic crystals and acicular aggregations of brown and white color; heulandite in brownish rhomboidal crystals; calcite, massive, of white, yellow, and green colors, and dog-tooth crystals of yellow color. There were many 
other crystals and massive specimens found, but either very small or insignificant in regard to quality or quantity.

I expect this place to be to the mineralogist what its near neighbor, Bergen Hill, world-famed, was fifteen years ago.

E. W. Perry.

\section{Color-Changes in Toads.}

IN Mr. Poulton's "Colors of Animals". he mentions (p. 83) that "the common frog can change its tints to a considerable extent." This recalls some experiments made in 1876 on common toads. Toads kept on dark grounds or in dark pen became dark, and on light grounds or in light pen became very much lighter in color. The arrangement of colors was not changed, but the whole seemed to grow lighter or darker. Red, blue, or other colors seemed to have no effect except as to their value as light-absorbers. Owing to the detailed notes being mislaid at this writing, it is impossible to give details of time; but my remembrance is that the change of shade took much longer than Mr. Poulton quotes for the frog. The experiment is an easy and interesting one to try. In fact, there is an immense field for young investigators in the question of color, because of the ease with which apparatus can be arranged and the number of species which as yet have not been tested. It is partly for this reason I record the above on toads. FREDERIC GARDNER, Jun.

Trinity College, Hartford, Conn., Dec. 17.

\section{The Cause of Rain.}

IN your issue of March 7, I refer, on p. 161, in a letter with the above title, to certain experiments which to my mind show conclusively that condensation takes place in saturated air by compression, and not by expansion.

As far as I am able to ascertain, the rain theories which my letter brings me in opposition to are based upon the supposition that the results of compressing and expanding saturated vapor or steam, as mentioned in the mechanical theory of heat, may be directly applied to saturated air.

That these $t w o$ so entirely different substances -- the one a pure gas, and-the other a compound or mixture of various gases, and both containing the same quantity of aqueous vapor for equal temperatures, pressures, and volumes - should act in the same way under compression and expansion seems to me hardly credible, and it $\mathrm{m}_{\star y}$ therefore be of interest to inquire whether any of your readers can quote the results of experiments on saturated air which are contrary to those I bave arrived at.

Brooklyn, N.Y, Dec. 20.

Franz A. Velschow, C.E.

\section{BOOK-REVIEWS.}

A Treatise on Electro-Metallurgy. By Walter G. MCMillan. London Charles Griffin \& Co.; Philadelphia, J. B. Lippincott Company. $12^{\circ}$. $\$ 3.50$.

THIs volume treats of the application of electrolysis to the plating, depositing, smelting, and refining of metals and to the reproduction of printing surfaces and art work, etc. That the author was well equipped for his work is evident to all who, with some understanding of the subject. glance through even a single chapter of the book. He believes evidently that in writing upon such subjects a technological rather than a technical treatment is required, for the matter is so lucidly set before the reader, that, even though he be a novice. he will bave no difficulty in comprehending: and this result is achieved without the use of technicalities, which, though useful in their proper place, are sometimes confusing to the general reader, and unnecessary for the expert. Still, in cases where the success or failure of a process is largely governed by strict attention to minute details, the author has not hesitated to introd lice such instructions as may be needful to guide the worker in the right direction In other words, the treatise is just such a combination of theory and / ractice as might be expected from one who. in addition to a knowledge of both sides of the subject, possessed the happy faculty of imparting that knowledge to others, as far as may be done through the medium of a book.

The first chapter is mainly historical, briefly sketching the progress of the art, from the rude beginnings of its chemical side, when it was discovered by the ancients that "certain metals became superficially coated with other metals when plunged into suitable solutions," down to its latest developments, not omitting the much-discussed Elmore process of producing seamless copper tubes. In this chapter the scope of the art of electro metaliurgy is stated to be, (1) to obtain a coherent and removable deposit on a mould the form of which it is desired to reproduce with accuracy,-electrotyping; (2) to obtain a thin but perfect and adhesire film of metal upon a metal of different character, in order to impart to it properties in which it is naturally deficient, electroplating; (3) to obtain the whole of a given metal from a substance containing it, either as a substitute for extraction by smelting, or for analytical or refining purposes; and (4) to dissolve metals, - either to remove an existing coat of one metal from the surface of another, or to effect the complete or partial solution of a homogeneous body superficially, as in electro-etching. This statement will give a yood idea of the scope of the treatise.

As a fair knowledge of chemistry and electricity is necessary to those who would understand the subject, the author introduces a chapter dealing in an elementary fashion with those sciences; not intended, of course. to take the place of text-book and laboratory study, but rather to lead up to it. The book is fully illustrated, and, in addition to a good index, has a glossary of substances commonly employed in electro-metallurgy, and many useful tables.

Outings at Odd Times: By Charles C. ABbott, M.D. New York, Appleton. $16^{\circ}$. $\$ 1.50$

To those acquainted with Dr. Abbott's previous works, this little volume needs no introduction. In spirit, if not in bookmaking sequence, it is one of a series of which, we trust, the end is not yet. To the nature-loving naturalist. not the perfunctory one, the reading of it will necessarily be a pleasure and an assistance; to the city dweller, with an occasional "day off," at any seasun of the year, it will prove an incentive to recreation-seeking in the best direction; to the a verage dweller in the country it will act as an "eye-opener" to much that is going on about him; while to any reader of ordinary intelligence the perusal of it cannot fail to be beneficial. It is the record of what a true lover of nature, in all its phases, has seen, heard. felt, and thought about on occasional outings at odd times, in odd places, and under what may be called odd circumstances. Beginning with a winter sunrise, and the midwinter minstrelsy of the birds that may be heard along the Delaware even when the snow covers the ground, he carries the reader around the cycle of the seasons, dwelling upon the pleasures that may be indulged in out of doors at almost any time, and even in the most unpromising of places. Moreover, there is much sound though unobtrusive philosophy in the book.

Dust and its Dangers. By Mitchell Prudden, M.D. New York, Putnam. $16^{\circ}$. 75 cents.

Dr. PrudDen's interesting little volume, "The Story of the Bacteria," is followed by another of equal interest and value. It has been written " with the purpose of informing people, in simple language, what the real danger is of acquiring serious disease - especially consumption - by means of dust-laden air, and how this danger may be avoided." The plan is well carried out, and the book will open the eyes of the people without needlessly alarming them. Chief attention is given to the consideration of the organic - bacterial and mould - constituents of dust-laden air. The "plate method" of biological analysis of air - i.e., five minutes' exposure to the air of a film of nutrient gelatine, and subsequent growth of colonies from the germs deposited - is simple and reasonably accurate, and yields interesting results. The relative numbers of bacteria in the air of the library of a private house, of a large retail dry-goods store, and of a cross-street in process of being cleaned, were 34,199 , and 3,810 . Under ordinary conditions, a New Yorker takes into his body with every twenty breaths 11 to 376 bacteria and moulds; and, when the dust is being stirred up, the number is excessive. The most of these are not disease-germs, but some may be so. Thanks to the ciliated cells of the air-passages, the phagocytes, the lymph-glands, and the digestive processes, the organic and inorganic dust-particles are 